\title{
Classical conditioning of the rabbit nictitating membrane response: Effects of reinforcement schedule on response maintenance and resistance to extinction
}

\author{
CHARLES M. GIBBS, SUE B. LATHAM, and I. GORMEZANO \\ University of Iowa, Iowa City, Iowa 52242
}

\begin{abstract}
Two experiments were conducted to assess the effects of the introduction of schedules of partial reinforcement (PRF), subsequent to continuous reinforcement training, on the maintenance and resistance to extinction of the rabbit's nictitating membrane CR. Substantial response levels were maintained by schedules of reinforcement as lean as $15 \%$, and the performance decrements, when observed to be reliable, could not be localized to the immediate effects of one, two, or three consecutive nonreinforced trials by the examination of conditional response probabilities. Moreover, reliable PRF extinction effects were obtained. The relevance of these findings to the purported empirical divergence of PRF effects on classical and instrumental conditioning were discussed.
\end{abstract}

The purpose of the present investigations was to determine the effects of introducing schedules of partial reinforcement (PRF) subsequent to continuous reinforcement (CRF) training on maintenance and resistance to extinction of the classically conditioned nictitating membrane response in the rabbit.

A persistent contention in the conditioning literature (Gray, 1975; Kimble, 1961, 1964; Razran, 1955; Terrace, 1973) has been that PRF has pronounced detrimental effects on acquisition and maintenance, and little effect on the resistance to extinction of classically conditioned, in contrast to instrumentally conditioned, especially free-operant, responses. However, the adequacy of support for this contention is questionable. Most important, the purported empirical divergence has rested upon comparisons of data obtained under markedly different reinforcement schedule manipulations. In free-operant research, a sustained high rate of responding under large-ratio or long-interval schedules and substantial resistance to extinction are generally obtained through multistage procedures initially involving response acquisition under CRF, followed by gradual reduction in the probability of reinforcement (e.g., Boren, 1961; Felton \& Lyon, 1966). In contrast, much of the classical conditioning research investigating the effects of PRF on acquisition, main-

This research was supported by National Science Foundation Grants GB-41531 and BNS 76-84561 to I. Gormezano. Requests for reprints should be sent to 1 . Gormezano, Department of Psychology, University of lowa, Iowa City, Iowa 52242. Portions of the data were reported in a paper read at the annual meeting of the Midwestern Psychological Association, Chicago, May 1976. tenance, and resistance to extinction has involved the administration of intermittent schedules from the inception of acquisition training (e.g., Gormezano \& Coleman, 1975; Grant \& Schipper, 1952). As yet, little research in classical conditioning has been directed to the question of whether response maintenance and resistance to extinction under PRF are enhanced by prior training under CRF. However, the outcomes of those few classical conditioning investigations involving transitions from CRF to PRF have been contradictory. Rapid decrements in human eyelid CRs following shifts from CRF to $50 \%$ PRF have been reported (e.g., Ross, 1959; Spence \& Trapold, 1961), and a parallel outcome has been obtained in classical aversive conditioning of fish (Gonzalez, Eskin, \& Bitterman, 1963). On the other hand, several infrahuman classical aversive conditioning studies have indicated no reliable response decrements following shifts from CRF to 50\% PRF, but no enhancement of resistance to extinction has been observed (Gonzalez, Longo, \& Bitterman, 1961; Gonzalez, Milstein, \& Bitterman, 1962; Longo, Milstein, \& Bitterman, 1962).

The contributions to response maintenance of reinforced and nonreinforced trials under post-CRF shifts to PRF have never been assessed by the examination of conditional response probabilities and, hence, the nature of the response decrements that have been observed following such shifts (e.g., Gonzalez, Eskin, \& Bitterman, 1963) remains unspecified. The examination of response probabilities conditional upon reinforced and nonreinforced trials would provide a means for contrasting learning formulations which postulate immediate inhibitory 
effects of nonreinforced trials under schedules of PRF (Spence, 1960; Thompson, 1960) with accounts which invoke more generalized, session effects of nonreinforced trials attributable, for example, to a stimulus generalization decrement (e.g., Capaldi, 1966; Sheffield, 1949) or to a reduction in "motivational level" (e.g., Reynolds, 1958; Spence, 1966a, 1966b) following reductions in percentage reinforcement. Specifically, localized inhibitory formulations must minimally predict a progressive decline in response probability with each successive nonreinforced trial under PRF schedules in which reinforced and nonreinforced trials are presented in random sequence. On the other hand, accounts of generalized CR decrements following a reduction in the probability of reinforcement would predict that, at least over a restricted range of consecutive nonreinforced trials, response probability should be independent of preceding trial events under randomly sequenced PRF training.

\section{EXPERIMENT 1}

The purpose of the experiment was to assess the effects of a broad range of reinforcement probabilities on the maintenance and resistance to extinction of the rabbit's classically conditioned nictitating membrane response in a three-stage design involving (1) acquisition under CRF, followed by (2) betweengroups shifts in percentage of reinforcement to $100 \%$, $50 \%, 25 \%, 5 \%$, or $0 \%$, and then (3) extinction for all groups. The investigation also attempted to localize the effects of PRF schedules on response maintenance by the examination of response probabilities conditional upon reinforced and nonreinforced trials.

\section{Method}

Subjects. The subjects were 72 naive male and female albino rabbits (Oryctolagus cuniculus), each 80-100 days old and weighing about $2.2 \mathrm{~kg}$ on arrival to the laboratory.

Apparatus. The apparatus and recording techniques have been described by Coleman and Gormezano (1971), who detail departures from earlier specifications (Gormezano, 1966). The CS was a 300 -msec, $1,000-\mathrm{Hz}, 82-\mathrm{dB}$ re $20 \mu \mathrm{N} / \mathrm{m}^{2}$ tone superimposed on a 70- $\mathrm{dB}$ background consisting of white noise masker and ventilation noise. The UCS was a 50-msec, 3-mA, 60- $\mathrm{Hz}$ shock delivered to the subject's paraorbital region through two stainless steel Autoclip sutures positioned $10 \mathrm{~mm}$ apart and $15 \mathrm{~mm}$ posterior to the dorsal canthus of the right eye. The CS-UCS interval was $250 \mathrm{msec}$.

Procedure. Prior to acquisition training, all subjects received 1 day of preparation, followed by a 2 -day recovery period and a single adaptation day. On the preparation day, a 2-mm-diam loop of monofilament nylon was sutured into the right nictitating membrane, the area posterior to the right eye was depilated, and the UCS electrodes were implanted. On the adaptation day, the subjects were restrained and placed in the conditioned chambers, and their base rates of responding were recorded at times corresponding to the observation intervals of the subsequent acquisition sessions. Twelve subjects were randomly assigned to each of six groups for the subsequent three stages of conditioning.
Stage I consisted of 3 100-trial days of acquisition training under CRF for all groups. In Stage II, 6 100-trial days of 100\%, 50\%, $25 \%, 15 \%, 5 \%$, or $0 \%$ reinforcement were administered to Groups C-100, C-50, C-25, C-15, C-5, and C-0, respectively. For all PRF groups, reinforced and nonreinforced trials were randomly determined within each 20-trial block for each day of Stage II training, with the restriction that every 10 th trial was a nonreinforced "test" trial. One day of $300 \mathrm{CS}$-alone extinction trials comprised Stage III for all groups. During all three stages of training, the intertrial intervals were randomized at values of $40,50,60,70$, and $80 \mathrm{sec}$, with a mean of $60 \mathrm{sec}$. A CR was defined as a $0.5-\mathrm{mm}$ extension of the nictitating membrane occurring during the first $250 \mathrm{msec}$ following CS onset for all trials. The amplitude of a CR was measured on each test trial by recording the maximum extension of the nictitating membrane during the first $1,000 \mathrm{msec}$ following CS onset.

\section{Results}

Figure 1 presents the mean percentage of CRs for all groups in 100-trial blocks across all three stages of the experiment. Inspection of the figure reveals that: (1) comparable performance levels were achieved by all groups in Stage $I$ acquisition; (2) during Stage II, the performance levels of Groups $\mathrm{C}-100, \mathrm{C}-50, \mathrm{C}-25$, and C-15 were essentially equivalent and stable, and while the level of Group C-5 declined over days, it remained superior to that of Group $\mathrm{C}-0$, the extinction control; and (3) Groups C-25 and C-50 exhibited the highest levels of performance in Stage III extinction, suggesting a partial reinforcement extinction effect (PREE).

The comparability of Stage I acquisition functions for all groups was supported by an analysis of variance of the percentage $C R$ data across days of Stage I training, in which the "dummy" variables of Groups and Groups by Days failed to reach even marginal levels of significance, $F(5,66)=1.05$ and $F(10,132)=0.83$, respectively. On the other hand, the response levels over 20-trial blocks of the first day (Day 4) of Stage II training (figure not shown) appeared to be directly ordered with respect to per-

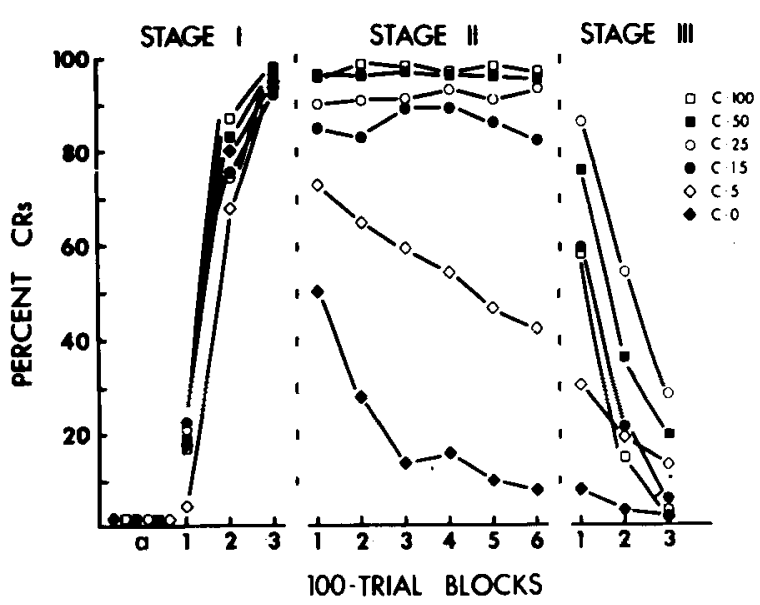

Figure 1. Percentage CRs as a function of 100-trial blocks of training in Stages I, II, and III. 
centage of reinforcement, except that the shift to the $50 \%$ schedule did not result in any response decrement relative to Group C-100. To assess the extent of the within-session response decrement, the difference in percentage CRs for the final 20-trial block of Stage I and the final 20-trial block of Day 4 was obtained for individual subjects in each group. An analysis of variance of these difference scores yielded a significant Groups effect, $F(5,66)=23.79$, $p<.01$, and a Tukey analysis revealed that, except for Group C-25, within-session response decrements in Groups C-100 and $\mathrm{C}-50$ were reliably smaller than those of all other contrast conditions and Groups C-15 and C-5 were less than that for Group $\mathrm{C}-0$ (critical difference $=$ $25.7 \%, \mathrm{p}<.05$ ).

An analysis of $C R$ frequency over the course of the 6 days of Stage II training, in 20-trial blocks, yielded a significant Groups effect, $F(5,66)=113.76, p<.01$. A subsequent Tukey analysis revealed that performance levels of Groups C-100, C-50, C-25, and C-15 were superior to those of Groups C-5 and C-0, but were not reliably different from one another (critical difference $=11.9 \%, p<.05$ ). Moreover, the Tukey analysis revealed that the performance difference between Groups C-5 and C-0 was reliable. Accordingly, these Tukey contrasts indicate that essentially comparable response levels were maintained by reinforcement schedules as lean as $15 \%$. The analysis of variance also yielded significant effects of Days, $\mathrm{F}(5,330)=7.71, \mathrm{p}<.01 ;$ Groups by Days, $\mathrm{F}(25,33)$ $=4.42, \mathrm{p}<.01 ;$ Blocks, $\mathrm{F}(4,264)=87.67, \mathrm{p}<.01$; and Groups by Blocks, $F(20,264)=8.17, p<.01$. All four effects primarily reflected the rather substantial between- and within-session response decrements for Groups C-5 and C-0.

An analysis of the Stage III percentage CR data in 20-trial blocks demonstrated a significant effect of Blocks $F(14,294)=99.72$, p $<.01$, simply reflecting the decline in response levels for all groups over the course of extinction. Additionally, reliable effects of Groups, $F(5,66)=11.20, p<.01$, and Groups by Blocks, $F(70,924)=7.54, p<.01$, were obtained, supporting the observation of differential rates of extinction among groups. A Tukey analysis indicated that Group C-25 performed at a reliably higher level than all other contrast conditions except Group C-50, while response levels for Groups C-50 and $\mathrm{C}-15$ were significantly higher than Group $\mathrm{C}-0$ (critical difference $=22.1 \%, \mathrm{p}<.05$ ). The nature of the PREE is more clearly revealed in Figure 2, which depicts CR frequency as a function of Stage II reinforcement probability for the first, final, and all three 100-trial blocks of Stage III training. (The CR frequency function for the second 100-trial block of Stage III was essentially identical to the overall function and, hence, is not presented.) Examination of the figure reveals responding to be an inverted

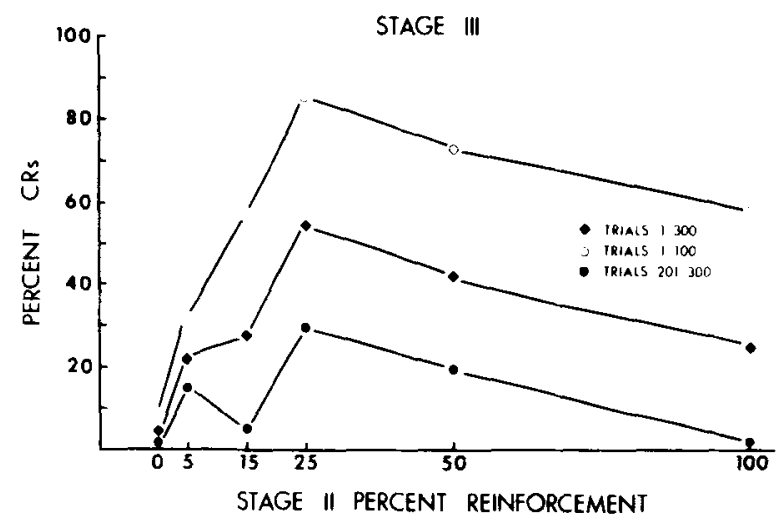

Figure 2. Percentage CRs as a function of Stage II percentage of reinforcement for the first, final, and all three 100-trial blocks in Stage III extinction.

U-shaped function of prior reinforcement probability, and a significant quadratic trend corroborated the reliability of the function, $F(1,66)=39.24$, $\mathrm{p}<.01$. Moreover, the remarkable similarity of the three functions indicates that the Stage II reinforcement schedule effect persisted throughout the course of extinction.

Examination of mean CR amplitudes (figure not shown) for the first, final, and all 6 days of Stage II training as functions of $50 \%, 25 \%, 15 \%, 5 \%$, and $0 \%$ reinforcement indicated that $\mathrm{CR}$ amplitude was a monotonic increasing function of probability of reinforcement, and an analysis of variance and trend of the overall amplitude function revealed significant effects of treatments, $F(4,55)=16.82, p<.01$, and of linear trend, $F(1,55)=67.62, p<.01$. Moreover, a subsequent Tukey analysis indicated that mean $C R$ amplitudes for Groups C-50 and C-25, while not reliably different from one another, were significantly greater than the $\mathrm{CR}$ amplitudes for Groups $\mathrm{C}-15, \mathrm{C}-5$, and $\mathrm{C}-0$ (critical difference $=3.00 \mathrm{~mm}$, $\mathrm{p}<.05)$. Additionally, the difference between Groups C-15 and C-0 was reliable.

To assess the contributions to $\mathrm{CR}$ frequency that may be localized to reinforced and nonreinforced trials, response probabilities conditional on one reinforced trial $(\mathrm{R}+1)$, as well as one $(\mathrm{N}+1)$, two $(\mathrm{NN}+1)$, and three (NNN + 1) consecutive nonreinforced trials, were obtained for individual subjects in Groups C-50, C-25, C-15, and C-5 across days of Stage II. (Only $\mathbf{R}+1$ conditional response probabilities were examined across all PRF contrasts due to limitations on the lengths of reinforced-trial runs in Groups C-25, C-15, and C-5.) The obtained conditional response probabilities revealed no evidence of systematic effects under any of the PRF schedules. Moreover, the substantial and reliable difference between Groups C-5 and C-100 in overall CR frequency in Stage II did not appear to be attribut- 
able to any unique decremental effects of the trial sequences examined. In fact, an analysis of variance of the Stage II conditional probabilities data for Group C-5 in 100-trial blocks revealed no significant effects of Conditionals and Conditionals by Days, Fs $<1.0$, indicating that the mean conditional probabilities for $\mathrm{R}+1$ (.601), $\mathrm{N}+1$ (.629), $\mathrm{NN}+1$ (.637), and NNN $+1(.598)$ trials were not reliably different from one another, nor were they differentiated across days of Stage II training.

\section{Discussion}

The present finding that the level of conditioned responding established under CRF may be maintained under reinforcement schedules as lean as $15 \%$ substantially extends the previous findings of CR maintenance under a $50 \%$ schedule (e.g., Longo, Milstein, \& Bitterman, 1962). Moreover, although the 5\% PRF schedule resulted in a progressive response decrement, the performance level of Group C-5 was clearly superior to that of Group C-0, the extinction control. Furthermore, the examination of conditional response probabilities failed to support conditioning formulations which localize response decrements following shifts from CRF to PRF to the inhibitory effects of each of the nonreinforced trials per se (Spence, 1960; Thompson, 1960). Specifically, such formulations would predict a progressive, although perhaps modest, decline in response probability following each successive nonreinforced trial, whereas no such systematic trends were observed under even the $5 \%$ reinforcement schedule.

The observation of a reliable PREE, attributable to the substantial resistance to extinction of Group $\mathrm{C}-25$, is counter to the numerous failures to observe a PREE following acquisition under PRF in infrahuman classical conditioning (e.g., Gormezano \& Coleman, 1975; Thomas \& Wagner, 1964; Vardaris, 1971; Vardaris \& Fitzgerald, 1969). However, such infrahuman classical conditioning investigations have generally examined only $50 \%$ schedules of reinforcement, and in the present investigation, overall extinction levels for Groups C-50 and C-100 were not reliably different. Moreover, such investigations have not involved shifts from CRF to PRF and then extinction. However, irrespective of such procedural differences, it has been argued (Spence, 1966a) that a PREE in classical conditioning will only be obtained when human subjects are employed, in that a PREE is purported to be dependent upon cognitive processes presumed to be reduced or absent in infrahumans. Clearly, the obtaining of a PREE with the present infrahuman classical conditioning preparation argues against the necessity of such a cognitive process.

\section{EXPERIMENT 2}

Since the data of the previous experiment revealed decremental effects on CR maintenance which could not be localized to the immediate effects of nonreinforced trials per se, consideration of more generalized effects of nonreinforcement, such as those postulated in stimulus generalization decrement hypotheses (e.g., Capaldi, 1966; Sheffield, 1949), would appear to be warranted. According to generalization decrement accounts, shifts from CRF to PRF introduce changes in the effective stimulus conditions for a CR. With continued training under PRF, the CR may be conditioned to the new stimulus elements and, hence, maintained. However, the degree of stimulus change, and therefore the difficulty of response maintenance, is purported to be directly dependent upon the amount of reduction in the probability of reinforcement. Although reliable withinsession response decrements during the first day of Stage II in Experiment 1 were observed for Groups $\mathrm{C}-15$ and $\mathrm{C}-5$, the subsequent recovery of response level for Group C-15, as well as the continued decline in the performance level of Group C-5, over days of PRF training suggest that the shift from CRF to 5\% PRF may have resulted in a degree of stimulus change which was particularly detrimental to the transfer of training. To the extent that a stimulus generalization decrement account is relevant to these findings, the reliable CR decrement observed for Group C-5 may be attenuated by procedures in which the reduction in percentage reinforcement from CRF to 5\% PRF is gradual, rather than abrupt. Accordingly, the purpose of the present investigation was to assess the implications of stimulus generalization decrement hypotheses to response maintenance by employing a multistage reinforcement-shift procedure, in which subjects were advanced from CRF to 5\% PRF and, subsequently, extinction by successive $10 \%$ decreases in the probability of reinforcement.

\section{Method}

Subjects. The subjects were 33 naive male and female albino rabbits, each 80-100 days old and weighing approximately $2.2 \mathrm{~kg}$ on arrival.

Apparntus and Procedure. The apparatus, general procedures, and stimulus events were the same as in the previous experiment. Eleven subjects were randomly assigned to each of three groups. The acquisition training administered to all subjects in Stage I consisted of 560 -trial days of CRF and a 6th day of $95 \%$ reinforcement. In Stage II, Group E (extinction) was immediately subjected to 18 days of $60 \mathrm{CS}$-alone extinction trials, while Group C (CRF) received 1860 -trial sessions at a $95 \%$, rather than $100 \%$, reinforcement level to permit collection of amplitude data on three nonreinforced test trials per session. Group P (PRF) also received 18 days of training, but each of 2 days of training were at progressively decreasing percentages of reinforcement of $85 \%, 75 \%, 65 \%, 55 \%, 45 \%, 35 \%, 25 \%, 15 \%$, and $5 \%$. For Group $P$, reinforced trials were randomly determined for each 
2-day block, with the restrictions that the percentage of reinforcement was constant for each 20-trial block within a given session and that every 20th trial was a nonreinforced test trial. In Stage III, Groups $\mathrm{C}$ and $\mathrm{P}$ were subjected to 10 days of $60 \mathrm{CS}$-alone extinction trials.

\section{Results}

Figure 3 presents the percentage of CRs for all groups in 2-day blocks across the three stages of the experiment. Examination of the figure reveals that: (1) acquisition performance levels in Stage I were essentially identical among groups; (2) in Stage II, Group $\mathrm{E}$ demonstrated an orderly extinction function, whereas the relatively stable $C R$ frequency functions for Groups $\mathrm{C}$ and $\mathrm{P}$ overlapped extensively, diverging only during the final 2-day block; and (3) although the response level for Group $C$ was clearly superior to that of Group $P$ for the first 2-day block of Stage III extinction training, the CR frequency functions converged and overlapped during subsequent trial blocks, suggesting interactive evidence for a PREE.

An analysis of variance performed on the CR frequency data of Stage I failed to reveal any significant sources of variation ( $\mathrm{ps}>.05$ ), thus supporting the observation of equivalent response levels among the ("dummy") groups. However, an analysis of variance of percentage CRs in 2-day blocks of Stage II yielded significant effects of Blocks, $\mathrm{F}(8,240)=20.05, \mathrm{p}<.01 ;$ Groups, $\mathrm{F}(2,30)=355.85$, $\mathrm{p}<.01$; and Groups by Blocks, $\mathrm{F}(16,240)=12.14$, $\mathrm{p}<.01$. To localize significant contributors to the effects of Groups and Groups by Blocks, tests of the simple effects of reinforcement condition were made which indicated that the Groups effect was reliable within each 2-day block of Stage II training, Fs $(2,140)$ $\geqslant 4.62$, ps $<.05$. Subsequent Tukey analyses of the simple Groups effect indicated that the performance levels of Groups $C$ and $P$, while significantly higher than that of Group E over each trial block, did not differ reliably until the final block of Stage II, at which time a $5 \%$ schedule of reinforcement was in effect for Group P (critical difference $=12.3 \%$, $\mathrm{p}<.05$ ).

Given the reliable difference in performance levels of Groups $C$ and $P$ prior to Stage III training, the extinction percentage $C R$ data for these conditions were transformed on the basis of performance levels for the final 2-day block of Stage II according to the shape-function method of Anderson (1963). An analysis of variance of the transformed $C R$ frequency data for Groups $C$ and $P$ revealed significant effects of Blocks, $F(4,80)=43.05, p<.01$, and Groups by Blocks $F(4,80)=2.57, p<.05$, but an unreliable Groups effect, $F<1.0$. Hence, although a PREE in the form of a significant treatments effect was not obtained, the interactive evidence for a PREE was reliable.

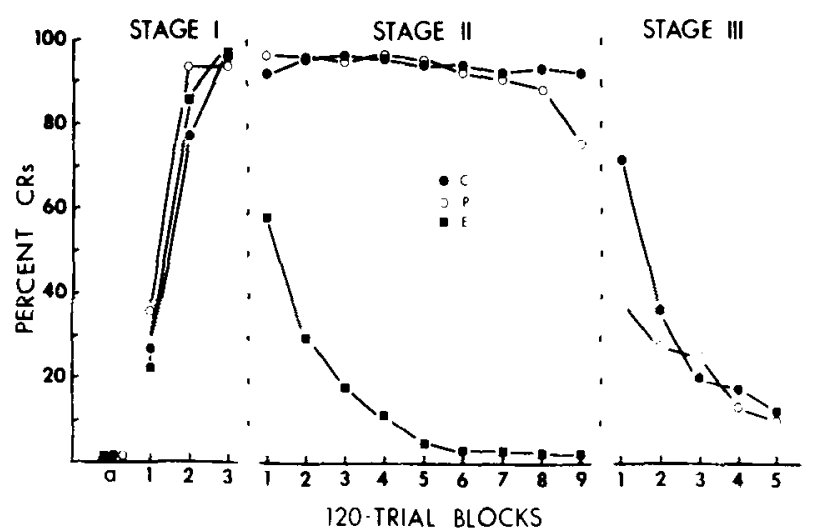

Figure 3. Percentage CRs as a function of 2-day blocks in Stages I, II, and III.

Examination of mean CR amplitudes for all groups for the final day of Stage I acquisition training and for 2-day blocks in Stage II (figure not shown) and appropriate statistical analyses revealed that the ("dummy") group mean amplitudes were essentially equivalent prior to Stage II $(F<1.0)$; and the $C R$ amplitude functions for Groups $C$ and $P$ diverged markedly and reliably only for the final block of Stage II as indicated by a significant effect of Groups by Blocks, $F(8,160)=4.08, p<.01$, and the localizing of the significant interaction by tests of the simple effects to the final 2-day block of Stage II, $F(1,38)=7.48, p<.01$, where the $5 \%$ schedule of reinforcement was in effect for Group $P$.

As in Experiment $1, \mathrm{R}+1, \mathrm{~N}+1, \mathrm{NN}+\mathrm{I}$, and NNN +1 conditional response probabilities were obtained for individual subjects in Group P across 2-day blocks of Stage II. Also, as in Experiment 1, no systematic differences in conditional response probabilities were observed either within or across trial blocks of PRF training. Moreover, even where Group $P$ revealed reliable $C R$ decrements under the $5 \%$ reinforcement schedule, no reliable differences were observed $(\mathrm{F}<1.0)$ among the $R+1(.854)$, $\mathrm{N}+1(.886), \mathrm{NN}+1(.885)$, and NNN $+1(.871)$ conditional response probabilities.

\section{GENERAL DISCUSSION}

The principal findings of the present experiments were: (1) performance levels established under CRF, in terms of CR frequency (Experiments 1 and 2) and $C R$ amplitude (Experiment 2), were maintained by reinforcement schedules as lean as $15 \%$; (2) PREEs, both as a reliable overall difference in extinction $C R$ frequency between Groups C-25 and C-100 in Experiment 1 and as a reliable Groups by Blocks interaction between Groups $P$ and $C$ in Experiment 2, were obtained; and (3) response decrements observed under the $5 \%$ reinforcement schedules in both experiments 
could not be localized to the immediate effects of one, two, or three consecutive nonreinforced trials.

The present findings of response maintenance with gradual or abrupt shifts to a PRF schedule as lean as $15 \%$ are analogous to findings in the free-operant literature where shaping and pretraining procedures consisting of CRF have typically preceded shifts to various PRF schedules (cf. Honig, 1966). Accordingly, the observation of a high level of response maintenance despite rather dramatic reductions in the probability of reinforcement argues against the characterization of PRF effects in classical conditioning as yielding labile CRs. This characterization has been presumed to provide an empirical basis for differentiating classical and free-operant conditioning paradigms (e.g., Kimble, 1961, 1964; Terrace, 1973) as well as support for the contention that the paradigms involve different learning mechanisms (Gray, 1975; Kimble, 1961, 1964).

Although the degree of response maintenance in the present investigations under low PRF schedules was substantial, performance decrements were obtained under both abrupt and gradual post-CRF shifts to 5\% PRF. However, it is imortant to note that the present reinforcement-shift procedures to $5 \%$ PRF were determined a priori and instituted on a group basis. If stimulus generalization decrements are produced by a shift from one schedule of reinforcement to a leaner schedule (e.g., Capaldi, 1966; Sheffield, 1949), a high response level may nevertheless be reestablished with continued training under that PRF schedule. That is, to the extent that the degree of stimulus change introduced by such a schedule shift is not dramatic and that reinforcement is continued in the presence of the new stimulus elements associated with the leaner PRF schedule, the new stimulus elements should eventually acquire substantial CR-evoking capabilities. On the other hand, a subsequent reduction in the percentage of reinforcement prior to the restabilization of conditioned responding would be assumed to produce further stimulus change and, hence, further disruption of responding. Accordingly, a reinforcement-shift procedure in which the reduction in reinforcement probability is instituted on the basis of stable responding determined by (1) group mean performance level or (2) individual response protocols, procedures which are commonly employed in operant research (cf. Felton \& Lyon, 1966; Ferster \& Skinner, 1957) may result in substantial $C R$ maintenance under percentages of reinforcement as low as $5 \%$. In fact, implication 1 has been subjected to preliminary assessment. Rabbits $(n=5)$, following acquisition of the nictitating membrane response under CRF, were advanced successively through reinforcement levels of $50 \%, 35 \%, 25 \%, 20 \%, 15 \%, 10 \%$, and $5 \%$. Each schedule shift was instituted only after the group mean $C R$ frequency and amplitude had stabilized over two consecutive 60-trial training sessions at values within the $95 \%$ confidence limits of the levels of responding revealed for the final 2 days of CRF (i.e., 95\%) training. Response maintenance was observed under a reinforcement schedule as lean as $10 \%$; however, as in the present experiments, a $5 \%$ schedule failed to maintain responding. Whether a reinforcement-shift procedure based on implication 2, of examining individual response protocols, would yield different outcomes remains to be determined.

Considering the effects of schedules of PRF on extinction performance, it is interesting to note that the inverted $U$ shape of the extinction percentage reinforcement-CR frequency function obtained in Experiment 1 was similar to that obtained under acquisition reinforcement schedules of $25 \%, 50 \%$, $75 \%$, and $100 \%$ for human eyelid conditioning by Grant and Schipper (1952). To account for their inverted U-shaped extinction function, Grant and Schipper advanced a two-process formulation of resistance to extinction, which incorporated notions of (1) the relative ease of discrimination of the onset of extinction training, and (2) preextinction response strength. Apparently, Grant and Schipper (1952) intended the discrimination process to entail some unique perceptual or cognitive response made to the transition from acquisition to extinction. However, the adequacy of that formulation of the discrimination process has been questioned by results from both discrete-trial instrumental (e.g., Jenkins, 1962; Theios, 1962) and classical (Perry \& Moore, 1965) conditioning investigations, in which PREEs have been observed despite the interpolation of CRF trial blocks between acquisition under PRF and extinction, an operation which should attenuate the difference between PRF and CRF conditions in the discriminability of stimulus conditions associated with the instituting of extinction.

The notion on preextinction response strength, on the other hand, is an integral part of uniprocess stimulus generalization decrement hypotheses (e.g., Capaldi, 1966; Sheffield, 1949). According to such accounts, a CR reinforced in the presence of one set of stimulus conditions will, through stimulus generalization, be less likely to occur as these conditions are progressively modified over the course of extinction. While the degree of stimulus generalization is presumed to be a direct function of the similarity of stimulus conditions under acquisition and extinction, the amount of generalized habit strength in extinction is dependent upon the overall level of habit strength at the end of reinforced training. With regard to Experiment 1, a stimulus generalization decrement formulation would argue, for example, that while the stimulus conditions prevailing under 
$15 \%$, in contrast to $25 \%$ reinforcement, were more similar to those encountered in extinction, greater resistance to extinction would be expected for Group C- 25 because the $15 \%$ reinforcement schedule did not produce as much habit strength. In fact, the observation of a reliable difference in mean $C R$ amplitudes in Stage II between Groups C-25 and $C-15$ suggests that the $25 \%$ schedule of reinforcement may have resulted in greater habit strength at the beginning of extinction training.

\section{REFERENCES}

ANDerson, N. H. Comparison of different populations: Resistance to extinction and transfer. Psychological Review, 1963, 70, 162-179.

Boren, J. J. Resistance to extinction as a function of the fixed ratio. Journal of Experimental Psychology, 1961, 61, 304-308.

Capaldi, E. J. Partial reinforcement: $A$ hypothesis of sequential effects. Psychological Review, 1966, 73, 459-477.

Coleman, S. R., \& Gormezano, I. Classical conditioning of the rabbit's (Oryctolagus cuniculus) nictitating membrane response under symmetrical CS.US interval shifts. Journal of Comparative and Physiological Psychology, 1971, 77, 447.455.

Felton, M.. \& Lyon, D. O. The post-reinforcement pause. Journal of the Experimental Anatysis of Behavior, 1966, 9, $131-134$.

Ferster. C. B.. \& Skinner, B. F. Schedules of reinforcement. New York: Appleton-Century-Crofts, 1957.

Gonzalez, R. C., Eskin, R. M., \& Bitterman, M. E. Further experiments on partial reinforcement in the fish. American Journal of Psychology, 1963, 76. 366-375.

Gonzalez, R. C., Longo, N., \& Bitterman, M. E. Classical conditioning in the fish. Exploratory studies of partial reinforcement. Joumal of Comparative and Physiological Psychology, 1961, 54, 452-456.

Gonzalez, R. C.. Milstein, S., \& Bitterman, M. E. Classical conditioning in the fish: Further studies of partial reinforcement. American Journal of Psychology, 1962, 75, 421-428.

Gormezano, 1. Classical conditioning. In J, B. Sidowski (Ed.), Experimental methods and instrumentation in psychology. New York: McGraw-Hill, 1966.

Gormezano, I., \& Coleman, S. R. Effects of partial reinforcement on conditioning, conditional probabilities, asymptotic performance. and extinction of the rabbit's nictitating membrane response. Pavlovian Journal of Biological Science, 1975, 10. 13-22.

Grant, D. A. \& Schipper, L. M. The acquisition and extinction of conditioned eyelid responses as a function of the percentage of fixed-ratio random reinforcement, Joumal of Experimental Psychology, 1952, 43, 313-320.

GRAY, J. A. Elements of a two-process theory of learning. New York: Academic Press. 1975.

Honig, W. K. Operant behavior. New York: AppletonCentury-Crofts, 1966.

JENKINS, H. M. Resistance to extinction when partial reinforcement is followed by regular reinforcement. Jourmal of Experimental Psychology, 1962, 64, 441-450.
KIMBLE, G. A. Hilgard and Marquis' conditioning and learning. New York: Appleton-Century-Crofts, 1961.

Kimble, G. A. Categories of learning and the problem of definition. In A. W. Melton (Ed.), Categories of human learning. New York: Academic Press, 1964.

Longo, N., Milstein, S., \& Bitterman, M. E. Classical conditioning in the pigeon: Exploratory studies of partial reinforcement. Journal of Comparative and Physiological Psychology, 1962, 55, 983-986.

Perry, S, L., \& Moore, J. W. The partial-reinforcement effect sustained through blocks of continuous reinforcement in classical eyelid conditioning. Journal of Experimental Psychol. ogy. 1965, 69, 158-161.

Razran, G. Operant vs. classical conditioning. American Journal of Psychology, 1955, 68, 489-490.

Reynolds, W. F. Acquisition and extinction of the conditioned eyelid response following partial and continuous reinforcement. Journal of Experimental Psychology, 1958, 55 $335-341$.

Ross. L. E. The decremental effects of partial reinforcement during acquisition of the conditioned eyelid response. Journal of Experimental Psychology, 1959, 57, 74-82.

Sheffield, V. F. Extinction as a function of partial reinforcement and distribution of practice. Journal of Experimental Psychology, 1949, 39, 511-526.

SPENCE, K. W. Behavior theory and leaming: Selected papers. Englewood Cliffs: Prentice-Hall, 1960.

SPENCE, K. W. Cognitive and drive factors in the extinction of the conditioned eyeblink in human subjects, Psychological Review, 1966, 73. 445.458. (a)

SPENCE, K. W. Extinction of the human eyelid CR as a function of presence or absence of the UCS during extinction. Journal of Experimental Psychology, 1966, 71, 642-648. (b)

Spence, K. W., \& Trapold, M. A. Performance in eyelid conditioning as a function of reinforcement schedules and changes in them. Proceedings of the National Academy of Sciences, 1961, 47, 1860-1868.

Terrace, H. S. Classical conditioning. In J. A. Nevin \& G. S. Reynolds (Eds.), The study of behavior: Leaming, motivation. emotion, and instinct. Glenview, IIl: Scott, Foresman, 1973.

Theios, J. The partial reinforcement effect sustained through blocks of continuous reinforcement. Joumal of Experimental Psychology, 1962. 64, 1-6.

Thomas, E., \& Wagner, A. R. Partial reinforcement of the classically conditioned eyelid response in the rabbit. Journal of Comparative and Physiological Psychology, 1964, 58, 157-158.

Thompson, M. E. A two-factor theory of inhibition. Psychological Review, 1960, 67, 200-206.

VARDARIS. R. M. Partial reinforcement and extinction of heart rate deceleration in rats with the US interpolated on nonreinforced trials. Learning and Motivation, 1971, 2, 280-288.

VARDARIS, R. M., \& FitzGerald, R. D. Effects of partial reinforcement on a classically conditioned eyeblink response in dogs. Journal of Comparative and Physiological Psychology. $1969,67,531-534$.

(Received for publication September 7, 1977; revision accepted November 3, 1977.) 